\title{
ANALYSIS AND COMPARISON THE METHODS OF DETERMINING RELIABILITY OF CRITICAL POINTS HELICOPTER STRUCTURE \\ ANALIZA I PORÓWNANIE METOD WYZNACZANIA NIEZAWODNOŚCI PUNKTÓW KRYTYCZNYCH STRUKTURY ŚMIGLOWCA
}

\author{
Marta Woch \\ Instytut Techniczny Wojsk Lotniczych \\ marta.woch@itwl.pl
}

\begin{abstract}
In this work, algorithms have been used to compare the methods for determining reliability of critical points. Generalized models Stress-StrengthInterference (SSI) and Stress-Strength-Time (SST) have been analyzed. Input to the algorithms, stress and strength were generated by using the Markov chain model based on actual flight records. With this approach methods of determining the reliability of critical points of a helicopter's structure are justified.
\end{abstract}

Keywords: reliability, critical points, algorithms

Streszczenie: $W$ pracy tej dokonano próby porównania algorytmów metod wyznaczania niezawodności punktów krytycznych. Poddano analizie uogólnione modele Model Stress-Strength-Interference (SSI) oraz Stress-Strength-Time (SST).

Dane wejściowe do algorytmów, czyli naprężenia $i$ wytrzymałości zostaly wygenerowane przy użyciu łańcuchów Markowa bazujacych na rzeczywistych zapisach danych $z$ lotu. Dzięki takiemu podejściu metody wyznaczania niezawodności punktów krytycznych struktury helikoptera maja rzeczywiste podstawy.

Stowa kluczowe: niezawodność, punkty krytyczne, algorytmy 
Analysis and comparison the methods of determining reliability ... Analiza i porównanie metod wyznaczania niezawodności ...

\section{Introduction}

Research on safety and therefore conduct of various health risk analyses has made a relatively recent entry into the fields of science. Safety research started with the realization that safety problems in many branches of technics and human life are common in character and therefore can be described in the same ways.

\section{Risk assessments methods}

Risk analysis has been done in accordance with the referenced method [1,2]. First, critic points of helicopter structure have been found, and one of them has been taken under observation. With respect to the laboratory data probability normal distribution has been proposed for steel strength. Value of the maximum principal stress in force mounting elements knots was obtained by using the model and calculations of the MSC Marc program. Based on experimental studies using Markov chain models the probability distribution function of internal stresses in the critical element was determined. Then the cumulative distribution for the probability distribution of stresses and strength were calculated. Reliability has been counted using the standard and generalized methods of Stress-Strength Interference (SSI) and Stress-Strength Time (SST).

\section{Mechanical stress - strength interference theory}

The basic assumption of the model is the conclusion that the helicopter component is damaged when the stress value is greater than the strength of this element. Stress $\mathrm{x}$ and strength $\mathrm{y}$ are random variables with probability distributions $f(x)$ and $g(y)$. Reliability of helicopter component can be defined as follows:

$$
R=P(y>x)
$$

where $\mathrm{P}$ is the probability of an event $\mathrm{y}>\mathrm{x}$. Having a relationship that defines the density, the expression can be written:

$$
R=P(y>x)=\int_{-\infty}^{+\infty} f(x)\left\{\int_{x}^{+\infty} g(y) d y\right\} d x
$$

The basic model assumes a normal distribution of random variables. Generalized model SSI (GSSI) assumes any distribution $f(x)$ and $g(y)$. It can be shown that the accepted model for such a reliability is reduced to the formula:

$$
R=P(y>x)=\int_{0}^{2 y} G(y) f(y) d y=\int_{0}^{2 y} F(y) g(y) d y
$$

where $F$ and $G$ are distribution functions of random variables $\mathrm{x}$ and $\mathrm{y}$. This model allows to determine the likelihood of damage to the helicopter component when the single force occurs. 


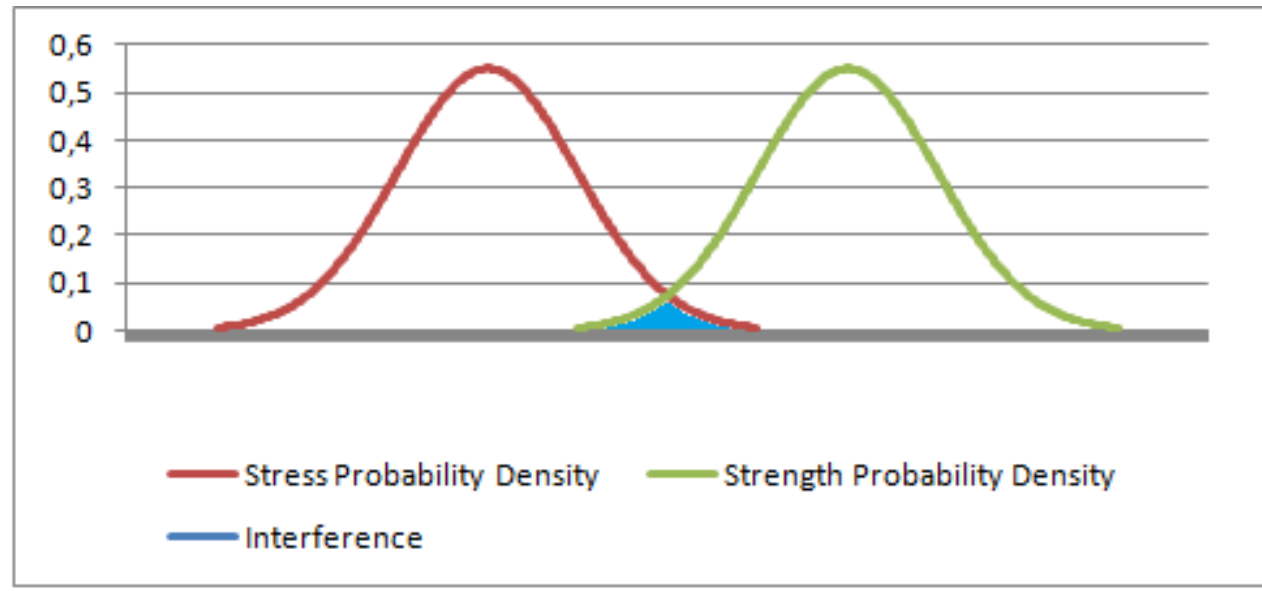

Fig. 1. Superimposing the Stress Graph on the Strength Graph shows the Stress/Strength Interference

\section{Mechanical stress-strength time theory}

This model takes into account the functional dependence of strength and stress on time. SSI models can be divided into:

- deterministic models - the stress and strength are unknown, or vary in a predictable manner,

- random-fixed models - stress and strength vary over time in a predictable way, but are not known constants, such as:

$$
y(t)=y_{0} \phi(t)
$$

where $y_{0}$ is a random variable and $\phi(t)$ is known function,

- random-independent models - the stress and strength are random variables whose values are statistically independent.

Under normal helicopter operating conditions we are dealing doing case SST $(2,3)$ where the stresses are described by random variable $x_{i}$, the value of $x_{1}, x_{2}, \ldots, x_{n}$ are statistically independent (independent random) and have the same distribution $f(x)$. Strength is described by a quasi-probabilistic (random-fixed) variable y with the known distribution $g(y)$. In this case, $\mathrm{R}_{\mathrm{n}}$ component reliability after the $\mathrm{n}$-th cycle is:

$$
R_{n}=P\left(E_{1}\right) \times P\left(E_{2}\right) \times \ldots \times P\left(E_{n}\right)=\left(\int_{0}^{\infty} g(y)\left\{\int_{0}^{y} f(x) d x\right\} d y\right)^{n}
$$

We assume that time is not a random variable and the length of the cycle is known. It was established also that the element does not age and does not damage with increasing number of cycles. The basic model assumes a normal distribution of random variables. Generalized model SST (GSST) assumes any distribution $f(x)$ and $g(y)$. It can be shown that the accepted model for such a reliability is reduced to the formula: 
Analysis and comparison the methods of determining reliability ...

Analiza i porównanie metod wyznaczania niezawodności ...

$$
R_{n}=\left[\int_{0}^{2 y} G(y) f(y) d y\right]^{n}=\left[\int_{0}^{2 y} F(y) g(y) d y\right]^{n}
$$

where $F$ and $G$ are distribution functions of random variables x and y.

\section{Markov chain model}

According to [3] a First-order Markov Chain (FCM) with finite space $E$ is a sequence of $E$-valued random variable $\left(X_{n}\right)_{n \in \mathrm{N}}$ such that the conditional distribution of $X_{n+1}$ knowing the discrete-time process $\left(X_{m}\right)_{m \leq n}$ is the same as the conditional distribution of $X_{n+1}$ given only $X_{n}$ :

$$
P\left(X_{n+1}=e_{n+1} \mid X_{n}=e_{n}, X_{n-1}=e_{n-1}, \ldots, X_{1}=e_{1}\right)=P\left(X_{n+1}=e_{n+1} \mid X_{n}=e_{n}\right)
$$

If $K_{c}$ is the number of load classes, the transition probabilities define a $K \times K$ - real matrix $\mathbf{P}$ such that:

$$
\mathrm{P}=\left(\begin{array}{cccc}
p_{1,1} & p_{1,2} & \cdots & p_{1, K} \\
p_{2,1} & p_{2,2} & \cdots & p_{2, K} \\
\cdots & \cdots & \cdots & \cdots \\
p_{K, 1} & p_{K, 2} & \cdots & p_{K, K}
\end{array}\right), \quad \sum_{j=1}^{K} p_{i, j}=1, \quad 0 \leq p_{i, j} \leq 1
$$

where $i=1, \ldots K, p_{i, j}=P\left(X_{n+1}=e_{j} \mid X_{n}=e_{i}\right)$.

Hidden Markov chains Models (HMM) [4,5] are an extension of the concept of Markov chains for which the observation of $X$ is not directly the state pertaining to $E$ but a probabilistic function of this state. It is a bivariate discrete-time process $\left\{S_{n}, X_{n}\right\}_{n>0}$.

\section{Calculation of the probability curve of strenght}

Samples of steel with the symbol 30HGSNA in the form of a rod with a diameter of $60 \mathrm{~mm}$ were endurance-fatigue tested. Actual tensile strength was obtained as follows:

Table 1. The results of actual tensile strength

\begin{tabular}{|c|c|c|c|c|c|c|c|c|c|c|c|}
\hline $\begin{array}{c}\text { No. } \\
\text { sampl } \\
\text { es }\end{array}$ & $2 / 05 / 1$ & $2 / 05 / 2$ & $2 / 05 / 3$ & $2 / 05 / 4$ & $2 / 05 / 5$ & $2 / 05 / 36$ & $2 / 05 / 61$ & $2 / 05 / 62$ & $2 / 05 / 63$ & $2 / 05 / 64$ & $2 / 05 / 132$ \\
\hline $\begin{array}{c}\mathbf{R}_{\mathrm{m}, \mathrm{r}} \\
{[\mathrm{MPa}]}\end{array}$ & 910 & 1695 & 1700 & 1685 & 1685 & 1730 & 1755 & 1750 & 1765 & 1800 & 1705 \\
\hline $\begin{array}{c}\text { No. } \\
\text { sampl } \\
\text { es }\end{array}$ & $2 / 05 / 133$ & $2 / 05 / 134$ & $2 / 05 / 135$ & $2 / 05 / 136$ & $2 / 05 / 137$ & $2 / 05 / 138$ & $2 / 05 / 139$ & $2 / 05 / 140$ & $2 / 05 / 141$ & $2 / 05 / 142$ & \\
\hline $\begin{array}{c}\mathrm{R}_{\mathrm{m}, \mathrm{r}} \\
{[\mathrm{MPa}]}\end{array}$ & 1805 & 1785 & 1785 & 1760 & 1800 & 1800 & 1800 & 1178 & 1170 & 1170 & \\
\hline
\end{tabular}


Based on the survey it can be stated that the actual tensile strength of steel 30HGSNA, obtained on samples heat treated under ZPP ITWL is: $R_{m, r}=1755 \mathrm{MPa}$ $\pm 0,34 \%$. Based on these results one can propose a normal probability distribution of strength with the mean equal $\mu=1755$ and variance $\sigma^{2}=400^{2}$.

$$
g(y)=\frac{1}{\sqrt{2 \pi 400^{2}}} \exp \left(\frac{-(x-1755)^{2}}{2 \cdot 400^{2}}\right)
$$

\section{Calculation of the probability curve of stress}

Critical element of the helicopter Mi-24 No. 8 was scanned using a 3D scanner ATOS III (Advanced Topometric System). Based on photogrammetric measurements the shapes of force elements were reproduced in a $\mathrm{CAD} / \mathrm{CAM}$ environment. Models of geometric elements of strength were performed in Unigraphics.

A finite-element method (FEM) model applied a unit axial force and the calculations were performed by using the MSC Marc programme. The maximum value of the maximum principal stress under the influence of force per unit amounted to $2880 \mathrm{~Pa}$.

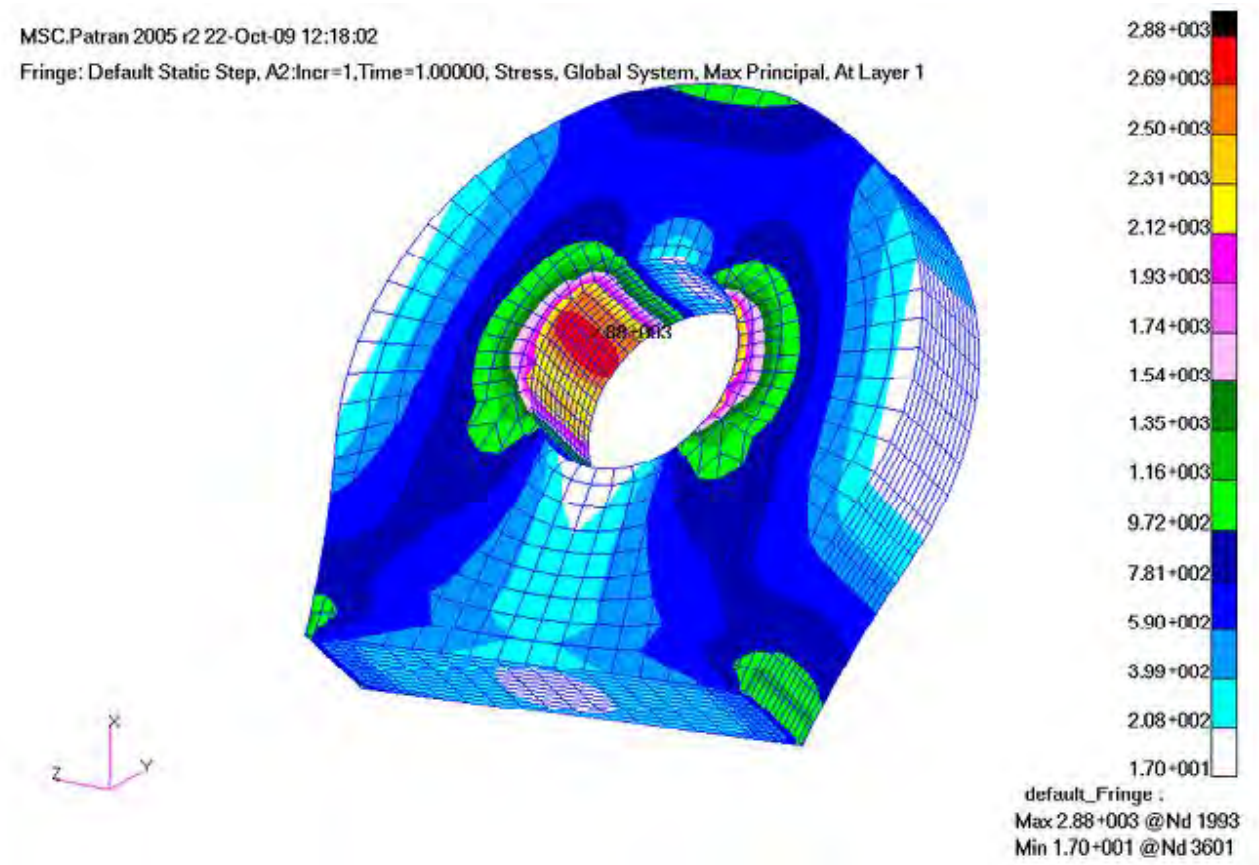

Fig. 2. Maximum principal stress distribution in a single node of the holes for mounting the elements. 
Analysis and comparison the methods of determining reliability ...

Analiza i porównanie metod wyznaczania niezawodności ...

Based on measurements of the strength of the flight test a stress histogram was generated.

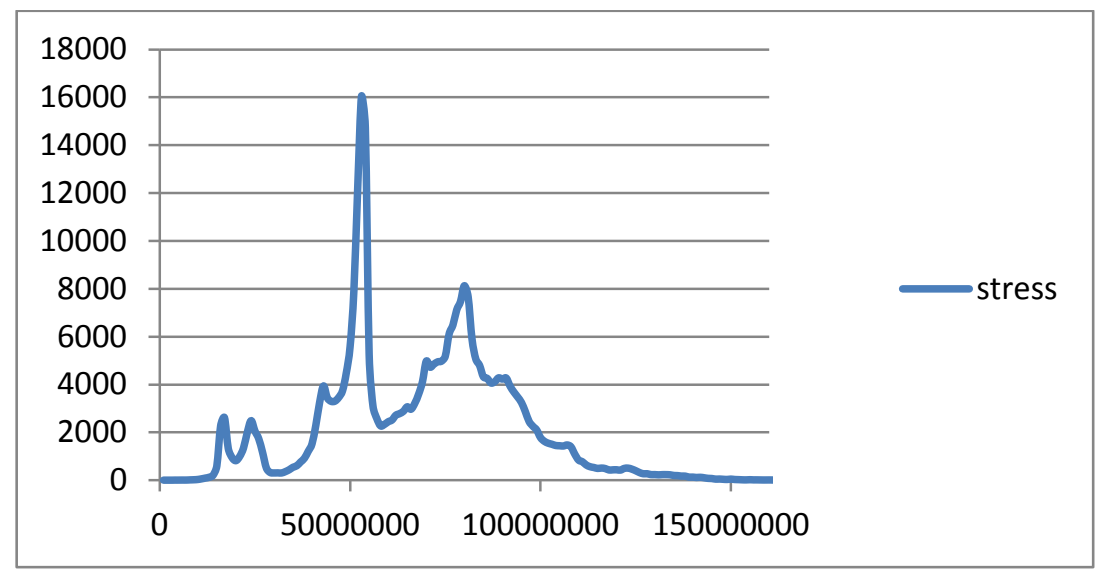

Fig. 3. Histogram of stress value.

Based on these results one can propose a normal probability distribution of stress with the mean equal $\mu=70$ and variance $\sigma^{2}=25^{2}$.

$$
f_{1}(x)=\frac{1}{\sqrt{2 \pi 25^{2}}} \exp \left(\frac{-(x-70)^{2}}{2 \cdot 25^{2}}\right)
$$

Based on the shape of the histogram of stress levels, the data set was split into $8 \mathrm{c}_{\mathrm{k}}$-classes. For the FCM model, all stress of load sequences pertaining to a given class $\mathrm{c}_{\mathrm{i}}$ are replaced by a unique stress value $\mathrm{s}_{\mathrm{i}}$.

Table 2. Probability distribution function after the application of the FCM model

\begin{tabular}{|l|l|l|l|l|l|l|l|l|}
\hline $\mathrm{X}\left(\mathrm{x}_{\mathrm{i}}\right)$ & 15 & 30 & 45 & 60 & 75 & 95 & 140 & 180 \\
\hline $\mathrm{p}_{\mathrm{i}}$ & 0,0034 & 0,0629 & 0,0698 & 0,2699 & 0,1733 & 0,3094 & 0,1084 & 0,0025 \\
\hline
\end{tabular}

The distribution function is:

$$
F_{2}(x)=\left\{\begin{array}{cc}
0 & x \leq 15 \\
0,0034 & 15<x \leq 30 \\
0,0663 & 30<x \leq 45 \\
0,1362 & 45<x \leq 60 \\
0,4062 & 60<x \leq 75 \\
0,5795 & 75<x \leq 95 \\
0,8890 & 95<x \leq 140 \\
0,9975 & 140<x \leq 180 \\
1 & x>180
\end{array}\right.
$$


For the HMC model the finite space $E$ was divided into 5 parts. After the calculation of stress cycles the resulting probability distribution can be estimated by following function $f_{3}$ :

$$
f_{3}(x)=\left\{\begin{array}{cc}
0 & x<10 \\
\frac{0,03}{\sqrt{2 \pi 1,5^{2}}} \exp \left(\frac{-(x-17)^{2}}{2 \cdot 1,5^{2}}\right) & 10 \leq x<20 \\
\frac{0,03}{\sqrt{2 \pi 1,5^{2}}} \exp \left(\frac{-(x-24)^{2}}{2 \cdot 1,5^{2}}\right) & 20 \leq x<30 \\
\frac{0,38}{\sqrt{2 \pi 3,6^{2}}} \exp \left(\frac{-(x-53)^{2}}{2 \cdot 3,6^{2}}\right) & 30 \leq x<60 \\
\frac{0,6}{\sqrt{2 \pi 12^{2}}} \exp \left(\frac{-(x-80)^{2}}{2 \cdot 12^{2}}\right) & x \geq 60
\end{array}\right.
$$

For which the distribution function is:

$$
F_{3}(x)=\int_{-\infty}^{x} f_{3}(x) d x
$$

\section{Calculation and results}

After applying the basic SSI model the probability of damage to the critical point is $2,16 \cdot 10^{-8}$. When the Generalized Stress-Strength-Interference models are used, the results depend on how the data stress was generated. If the data real from flights is used $\left(f_{l}\right)$, the probability of damage to the critical point is $7,78 \cdot 10^{-9}$. when the data is obtained using Markov chain models, I received the following probability of failure: $9,19 \cdot 10^{-9}$ and 5,38 $10^{-9}$ for First-order $\left(f_{2}\right)$ and Hidden Markov Chains $\left(f_{3}\right)$. After analysis using a SST model chance of failure is $1 \%$ after 465000 cycles for the general model SST. For generalized models SST results are as follows: 1290 000, 1090000,1850000 cycles respectively for the actual data from the flight, data generated using the FMC model and data generated using the HMC model.

\section{Conclusions}

Stress-Strength-Interference model allows to determine the likelihood of damage to the helicopter component when a single force occurs. Based on these assumptions, it will not apply in aviation where a stress on a specific element varies with time. In these models the aging process of the element is not included. Taking into account of this phenomenon would decrease strength, and thus decrease the number of cycles till failure. 
Analysis and comparison the methods of determining reliability ...

Analiza i porównanie metod wyznaczania niezawodności ...

Results obtained from generalized Stress-Strength-Interference and StressStrength-Time models are similar regardless of how the stress was generated from the basis of experimental data. They differ slightly from those obtained with standard models.

\section{References}

[1] AIRO SOFTWARE: Projekt badawczy nr PBR 03/2000/z.

[2] B. S. Spiegel: Safe - Life Reliability Design for Rotorcraft, Meeting on Fatigue Methodology III, Arizona, 1989.

[3] C. Mattrand, J-M. Bourinet, D. Theret: Analysis of Fatigue Crack Growth under Random Load Sequences Derived from Military In-flight Load Data, 26th ICAF Symposium, Montreal, 2011.

[4] O. Cappe, E. Moulines, T. Ryden: Interference in Hidden Markov Models. Springer Series in Statistics, 2005.

[5] L. Rabiner: A tutorial on hidden Markov Models and Selected Applications in Speech Recognition, In: Readings in Speech Recognition 2011.

Marta Woch MSc. Eng, Air Force Institute of Technology, graduated from Warsaw University of Technology in 2009. M.Sc. in Computer Science specialized in CAD/CAM System Design. She is engaged in development and implementation of IT systems to support aircraft maintenance, safety and reliability mamgement. 